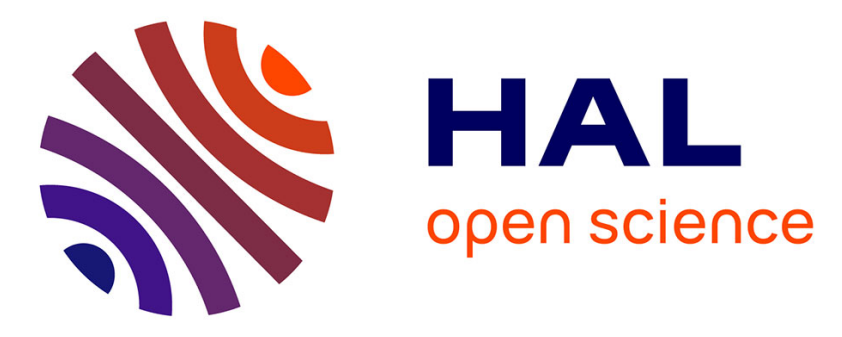

\title{
Introducing Functionality to Fluorinated Electroactive Polymers
}

Konstantinos Kallitsis, Thibaut Soulestin, Sylvie Tencé-Girault, Cyril Brochon, Eric Cloutet, Fabrice Domingues dos Santos, Georges Hadziioannou

\section{- To cite this version:}

Konstantinos Kallitsis, Thibaut Soulestin, Sylvie Tencé-Girault, Cyril Brochon, Eric Cloutet, et al. Introducing Functionality to Fluorinated Electroactive Polymers. Macromolecules, 2019, 10.1021/acs.macromol.9b01942 . hal-02344363

\section{HAL Id: hal-02344363 https://hal.science/hal-02344363}

Submitted on 14 Jan 2020

HAL is a multi-disciplinary open access archive for the deposit and dissemination of scientific research documents, whether they are published or not. The documents may come from teaching and research institutions in France or abroad, or from public or private research centers.
L'archive ouverte pluridisciplinaire HAL, est destinée au dépôt et à la diffusion de documents scientifiques de niveau recherche, publiés ou non, émanant des établissements d'enseignement et de recherche français ou étrangers, des laboratoires publics ou privés. 


\section{Introducing functionality to}

\section{Fluorinated Electroactive Polymers}

Konstantinos Kallitsis ${ }^{a}$, Thibaut Soulestin $^{b}$, Sylvie Tencé-Girault ${ }^{c, d}$, Cyril Brochon $^{a}$, Eric Cloutet $^{a}$, Fabrice Domingues Dos Santos ${ }^{b}$, Georges Hadziioannou $*^{a}$

${ }^{a}$ Laboratoire de Chimie des Polymères Organiques (LCPO UMR 5629), CNRS-Université de Bordeaux-Bordeaux INP, 16 Avenue Pey-Berland, 33607 Pessac Cedex, France

${ }^{b}$ Arkema-Piezotech, Rue Henri-Moissan, 69493 Pierre-Benite Cedex, France

${ }^{c}$ Laboratoire PIMM, Arts et Metiers, CNRS, Cnam, HESAM Université, 151 Bd de l'Hôpital, 75013 Paris, France

${ }^{d}$ Arkema, CERDATO, Route du Rilsan, 27470 Serquigny, France

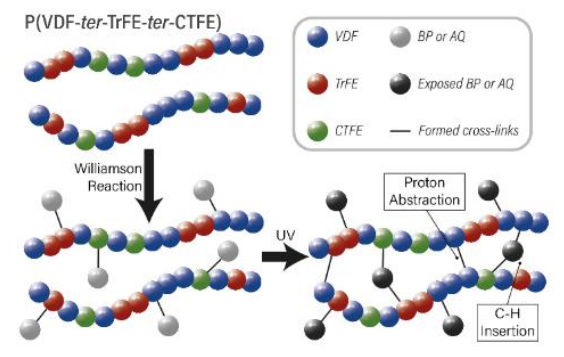

KEYWORDS. Electroactive, high-k, relaxor-ferroelectric, cross-linkable 


\begin{abstract}
Fluorinated Electroactive Polymers (FEPs) are amongst the most interesting insulating materials for the production of organic electronic devices. Their ability to tune their response to an applied electric field makes them appropriate for vastly different applications in electronics. However due to the chemical inertness of such polymers and the rather complex synthetic processes required for their production, introducing additional functionality to FEPs remains an open challenge. Here we present a facile way to introduce additional functionality to FEPs and more specifically photopatternability by a simple etherification method, which allows us to introduce almost any functional group on FEPs. Photo cross-linkable moieties were introduced on FEPs using this method, inducing photopatternability, while tuning their electroactive response with great property enhancement up to $60 \%$ in terms of relative permittivity in several cases.
\end{abstract}

\title{
INTRODUCTION
}

If flexible organic electronics are to be realized in massive scale, three classes of materials ought to be optimized. Those classes are conductors, semiconductors and insulators which are the three essential components for any electronic device. Organic conductors ${ }^{1}$ and semiconductors $^{2}$ have been extensively developed during the past 40 years, while research in insulators with high dielectric constant and thus high performance is lagging far behind. Fluorinated Electroactive Polymers (FEPs) are maybe the most prominent class of insulating polymers and are attracting increasingly high interest both in industrial and laboratory scale ${ }^{3}$. Poly(vinylidene fluoride) (PVDF) and it's copolymers dominate this group due to their excellent dielectric properties as well as their chemical and mechanical stability. However their electroactive properties, varying from ferroelectric ${ }^{4}$ to relaxor-ferroelectric ${ }^{5}$ significantly 
increase their scope of application. Due to the difficulty in controlling the synthesis of such polymers adding further functionality, although essential to broaden their application still remains an open challenge ${ }^{6-7}$. Some efforts towards this direction have been recently demonstrated by the preparation of block copolymers of $\mathrm{P}(\mathrm{VDF}-\mathrm{co}-\mathrm{TrFE})$ with polystyrene or poly(2-vinyl-pyridine) in order to tailor the electroactive response from ferroelectric to relaxorferroelectric and linear dielectric ${ }^{6}$. Despite the very interesting findings though, large increase in leakage current was observed for the prepared polymers, creating a main bottleneck for their potential application. Also the used solution polymerization processes for the polymerization of VDF and TrFE make that approach non compatible with industrial standards which rely exclusively on miniemulsion ${ }^{8}$ or suspension ${ }^{9}$ polymerizations in aqueous media. In other attempts to tune the electroactive properties of FEPs, grafting strategies have been explored, where side chains appear to induce antiferroelectric like behavior to the electroactive polymers, by providing an insulating layer to the ferroelectric crystals ${ }^{10-11}$. However, the controlled radical polymerization (ATRP) process used in those cases makes them unattractive for industrial scale as extensive purification steps, in order to remove all copper residues, can significantly increase the production costs. Grafting of polymer chain containing highly polarizable hydroxyl $(\mathrm{OH})$ groups have been reported to have positive impact both in the dielectric and ferroelectric properties of PVDF based fluoropolymers ${ }^{12}$, limited only by increased leakage current and a decrease in crystallinity.

An effort to introduce additional functionality to the electroactive properties, and more specifically photopatternability has been recently reported from our group ${ }^{13}$. In this approach photosensitive azide groups were grafted on relaxor-ferroelectric P(VDF-ter-TrFE-ter-CTFE) making it photo cross-linkable, while maintaining it's electroactive properties. Those polymers 
were used as negative photoresists in a photolithographic process, broadening the scope of application of FEPs. Despite all the advantages that this approach brought, some limitations hinder its potential for commercialization. Firstly, this approach provided a specific tool to graft azide groups on CTFE containing fluoropolymers, but no flexibility in terms of the grafted group was possible. The second and maybe even more important limitation is that cross-linking appears to have a detrimental impact on both the dielectric and ferroelectric properties of those polymers. Finally, the azide chemistry is also quite restricted at industrial level.

We were thus looking for an alternative approach that would allow us to introduce functionality on FEPs, while being versatile as of the grafted group and ideally maintain or even enhancing the electroactive properties.

\section{EXPERIMENTAL SECTION}

Materials. Unless otherwise stated all chemicals were purchased from Acros Organics or Merck chemicals and used without any further purification. The statistical terpolymers P(VDFter-TrFE-ter-CTFE) were provided by Arkema-Piezotech (France). Argon was supplied by Air Liquid with at least $99.99 \%$ purity.

Synthesis. Typical modification reactions were performed using standard schlenk techniques.

4-hydroxy benzophenone grafting reaction on P(VDF-ter-TrFE-ter-CTFE) (61.7/28.3/10): (1g) of terpolymer was dissolved in $25 \mathrm{ml}$ of acetone in a $50 \mathrm{ml}$ glass schlenk ampoule. 4-hydroxy benzophenone $(0.8 \mathrm{~g}, 4.0 \mathrm{mmol})$ and potassium carbonate $(0.7 \mathrm{~g}, 5.6 \mathrm{mmol})$ were mixed in acetone $(15 \mathrm{ml})$. The glass schlenk was sealed under argon and heated to $60^{\circ} \mathrm{C}$ in the dark for 1 hour. Then, the second solution was filtered and added to the first in order to remove the excess of the base. The glass ampoule was sealed and left in the dark at $60^{\circ} \mathrm{C}$ for 16 hours to react. Few drops of condensed $\mathrm{HCl}$ were added after the end of the reaction and the polymer was precipitated in 
water and washed with water, ethanol and chloroform for several hours to remove any impurities. Then it was dried in vacuum oven at $40^{\circ} \mathrm{C}$ for 12 hours.

2-hydroxy anthraquinone grafting reaction on P(VDF-ter-TrFE-ter-CTFE) (61.7/28.3/10): (5g) of terpolymer were dissolved in $100 \mathrm{ml}$ of dimethyl formamide (DMF) in a 250ml glass schlenk ampoule. 2-hydroxy anthraquinone $(1.4 \mathrm{~g}, 6.4 \mathrm{mmol})$ and potassium carbonate $(1.32,9.6 \mathrm{mmol})$ were mixed in dimethyl formamide (DMF) $(100 \mathrm{ml})$. The glass schlenk was sealed under argon and heated to $80^{\circ} \mathrm{C}$ in the dark for 1 hour. Then, the second solution was filtered and added to the first in order to remove the excess of the base. The glass ampoule was sealed and left in the dark at $80^{\circ} \mathrm{C}$ for 16 hours to react. The polymer was precipitated in water and then washed with water, ethanol and chloroform for several hours to remove any impurities. Then it was dried in vacuum oven at $40^{\circ} \mathrm{C}$ for 12 hours.

Instruments and Characterization. ${ }^{1} \mathrm{H}$ NMR and ${ }^{19} \mathrm{~F}$ NMR spectra were recorded on a Bruker Advance DPX $400 \mathrm{MHz}$ spectrometer. All samples were prepared in deuterated acetone (d6). FT-IR spectra were recorded on a Bruker Vertex 70 using diamond ATR spectroscopy. The differential scanning calorimetry (DSC) thermograms were recorded by a TA Instrument DSC Q100 RCS. The DSC analysis was performed from $0^{\circ} \mathrm{C}$ to $200^{\circ} \mathrm{C}$ at a heating or cooling rate of $10^{\circ} \mathrm{C} / \mathrm{min}$. A first heating ramp was used to erase the thermal history and solvents traces of the polymer powders, while the first cooling and second heating ramps were recorded. Broadband dielectric spectroscopy of metal-polymer-metal devices was performed on a Solartron 1260 A impedance analyzer. Displacement hysteresis loops of the metal-polymer-metal devices were recorded at room temperature using a TF Analyzer 2000E from aixACCT Systems. A continuous triangular wave with a frequency of $10 \mathrm{~Hz}$ was used. UV-Visible absorption spectra were recorded on self standing films using a Shimadzu spectrophotometer UV-3600. Atomic force 
microscopy (AFM) was performed on spincoated polymer films on a Dimension Fast Scan from Bruker in tapping mode. Photolitography was performed on an EVG6200 mask aligner. Film thicknesses were measured on a Bruker Dektak XT-A stylus profilometer.

Simultaneous SAXS-WAXS experiments were performed on the Xenocs Nano-inXider SW system in transmission mode using $\mathrm{Cu} \mathrm{K \alpha}$ radiation $(\lambda=1.54 \AA)$ from an X-ray microsource (GeniX3D) operating at $50 \mathrm{kV}-0.6 \mathrm{~mA}(30 \mathrm{~W})$. Scattering patterns were collected using the combination of two detectors Pilatus3 (Dectris) operating simultaneously in SAXS and WAXS positions. Distances between the sample and SAXS and WAXS detectors are fixed allowing a continuous q range between $0.005 \AA^{-1}$ and $4.2 \AA^{-1}\left(2 \theta\right.$ range between $0.07^{\circ}$ to $\left.62^{\circ}\right)$. The SAXS and WAXS profiles are treated to extract structural quantitative values: the long period, $L_{P}$, the interplanar distances, $\mathrm{d}$, and the crystallinity, $\chi_{\mathrm{c}}$. We have already published ${ }^{14}$ the detailed procedure used for the SAXS-WAXS quantitative analysis.

\section{Preparation of patterned thin films.}

Benzophenone containing P(VDF-ter-TrFE-ter-CTFE): A 4\% wt. solution of the benzophenone modified polymer (4.4\%) in cyclopentanone was spin-coated on a silicon wafer at $500 \mathrm{rpm}$ for $5 \mathrm{sec}$ and then at $1000 \mathrm{rpm}$ for $1 \mathrm{~min}$, yielding a $250 \mathrm{~nm}$ thick film. The wafer was soft baked before exposure at $130^{\circ} \mathrm{C}$ for 5 min and subsequently cross-linked by UV light under nitrogen, using a photo-lithographic mask. The applied UV dose was $6 \mathrm{~J} / \mathrm{cm}^{2}$. Then, the film was post exposure baked at $130^{\circ} \mathrm{C}$ for $5 \mathrm{~min}$. Finally, the patterned film was developed in a blend of one fifth cyclopentanone and four fifths isopropanol for $1 \mathrm{~min}$. Subsequently, the wafer was rinsed with isopropanol and dried with compressed air.

Anthraquinone containing $\mathrm{P}(\mathrm{VDF}-$ ter-TrFE-ter-CTFE): A $4 \%$ wt. solution of the anthraquinone modified polymer $(0.6 \%)$ in cyclopentanone was spin-coated on a silicon wafer at 
$500 \mathrm{rpm}$ for $5 \mathrm{sec}$ and then at $1000 \mathrm{rpm}$ for $1 \mathrm{~min}$, yielding a $250 \mathrm{~nm}$ thick film. The wafer was soft baked before exposure at $250^{\circ} \mathrm{C}$ for $5 \mathrm{~min}$ and subsequently cross-linked by UV light under nitrogen, using a photo-lithographic mask. The applied UV dose was $3 \mathrm{~J} / \mathrm{cm}^{2}$. Then, the film was post exposure baked at $250^{\circ} \mathrm{C}$ for $5 \mathrm{~min}$. Finally, the patterned film was developed in a blend of one fifth cyclopentanone and four fifths isopropanol for $1 \mathrm{~min}$. Subsequently, the wafer was rinsed with isopropanol and dried with compressed air.

Device fabrication. The metal-polymer-metal devices were fabricated as follows. Glass substrates were cleaned and sonicated in acetone and isopropanol for $15 \mathrm{~min}$. Then a layer of aluminum $(80 \mathrm{~nm})$ was evaporated as the bottom electrode using a thermal evaporator at a pressure of $1.10^{-6}$ mbar. Subsequently a $10 \%$ wt. solution polymer dielectric layer was spincoated at $500 \mathrm{rpm}$ for $5 \mathrm{sec}$ and then $1000 \mathrm{rpm}$ for $1 \mathrm{~min}$. An aluminum top electrode $(80 \mathrm{~nm})$ was evaporated, creating a metal-insulator-metal device with an area of $2 \mathrm{~mm}^{2}$. The devices were annealed at $110^{\circ} \mathrm{C}$ for $1 \mathrm{~h}$ and let to cool down slowly to room temperature.

\section{RESULTS AND DISCUSSION}

\section{Synthesis and chemical characterization}

To make the grafting of different groups on FEPs possible we developed a simple etherification reaction that would allow the grafting of any phenol containing functional group on the fluoropolymer's backbone. Similar approaches have been reported in literature for the modification of non-electroactive fluorinated polymers such as CTFE containing fluoropolymers. ${ }^{15}$ In our opinion, one of the main difficulties in developing such method is the use of bases in order to activate the phenol group, since FEPs are known to be prone to dehydrofluorination in the presence of bases ${ }^{16}$. To overcome this bottleneck we introduced a two-step approach (Scheme 1) in which the phenol containing functional group is treated with a 
base separately in order to activate the phenols and then transferred after filtration ${ }^{17}$ into a solution of the fluoropolymer, where the reaction occurs, while minimizing the effect of dehydrofluorination.

1.

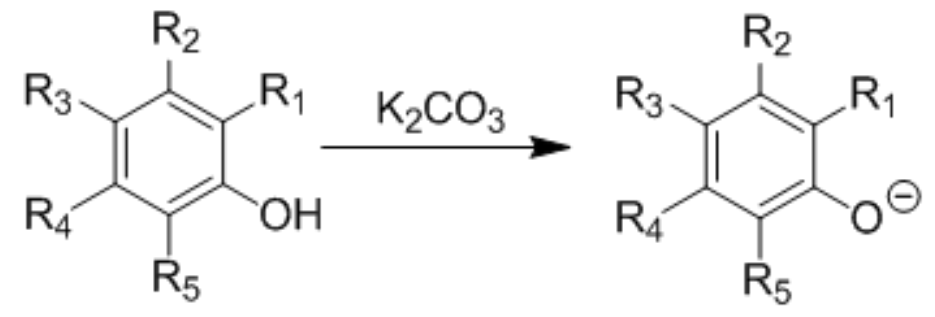

2.<smiles>[R]c1c([R])c([R])c([O-])c([R])c1[R]</smiles>

Scheme 1. Two step etherification reaction of functionalized phenols on P(VDF-ter-TrFE-terCTFE). First the phenol is deprotonated with the use of a base and subsequently filtered in a solution of the polymer, where the substitution and thus the grafting occur.

Since making fluoropolymers compatible with photolithography is a topic of increasingly high interest in order to broaden their scope of application we decided to graft hydroxy-functionalized photoinitiators on the fluoropolymers in order to make them photo-crosslinkable. We chose to use two different photoinitiator molecules, namely benzophenone (BP) and anthraquinone (AQ), as polymers bearing those molecules as side groups are known to act as negative photoresists ${ }^{18-}$ 19. The hydroxy-functionalized photoinitiators are shown in Scheme 2. 

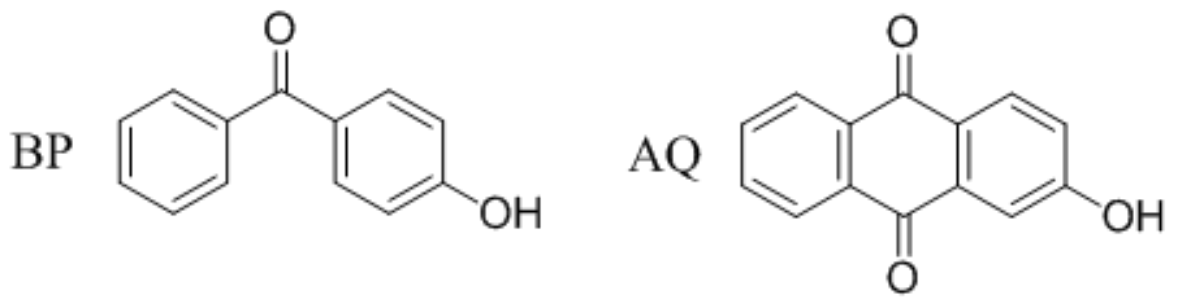

Scheme 2. Chemical structures of 4-hydroxy benzophenone (BP) and 2-hydroxy anthraquinone (AQ).

Fluoropolymers with different grafting degree of the two photoinitiators were synthesized by varying the feeding ratios. All the synthesized polymers were characterized by ${ }^{1} \mathrm{H}$ and ${ }^{19} \mathrm{~F}$ NMR as well as FT-IR as shown in Figure 1 and Figures $\mathrm{S}$ 1, 3. The presence of the aromatic photoinitiator (PI) led to the appearance of the signals at 7-8 ppm at the ${ }^{1} \mathrm{H}$ NMR (Figure 1a, b)(VDF-CTFE H-T peak), which was then used to calculate the grafting degrees. New bands were also observed at the FT-IR spectra (Figure 1b, d), indicating the presence of the C-H and $\mathrm{C}=\mathrm{O}$ groups of the photoinitiators with progressively increasing intensity with PI content. At the same time the appearance of unsaturation was observed both in the FT-IR (Figure 1b, d) with the band at $1720 \mathrm{~cm}^{-1}$ and from the ${ }^{1} \mathrm{H}$ NMR (Figure 1a, c), with the appearance of signals at 6-6.7 ppm and ${ }^{19}$ F NMR (Figures S 1, 3). The absence of any $-\mathrm{OH}$ traces both in the FT-IR and the NMR strongly suggests that all the PI groups are successfully grafted on the fluoropolymer chain. That was further verified by size exclusion chromatography (Figures S 2,4) where, while the pristine fluoropolymer has no absorption in the UV detector, the fluoropolymer grafted with photoinitiators absorbs in UV confirming that the grafting reaction was successful. 

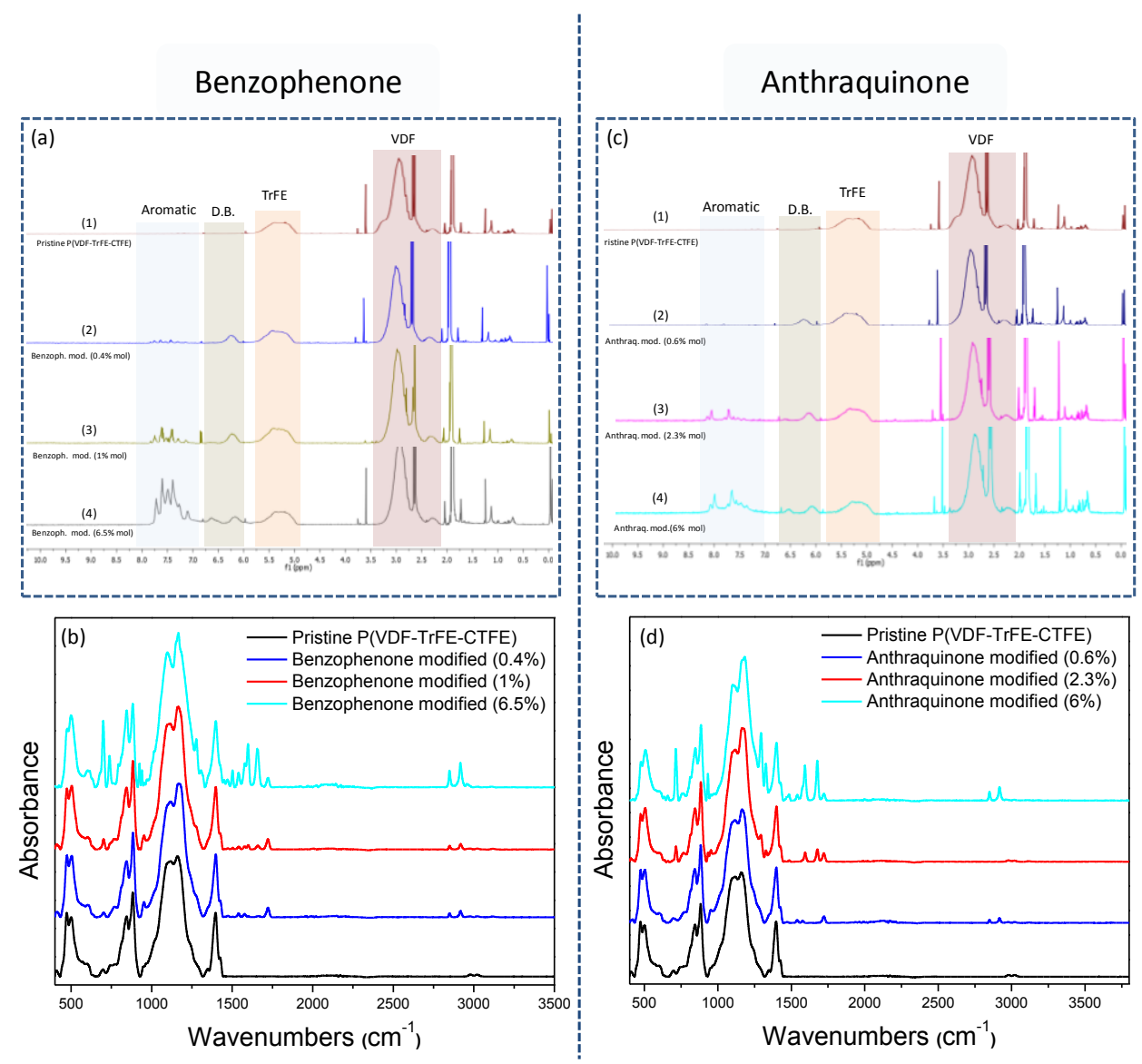

Figure 1. ${ }^{1} \mathrm{H}$ NMR $\left(400 \mathrm{MHz}\right.$, acetone- $\left.\mathrm{d}_{6}\right)(\mathrm{a}, \mathrm{c})$ and ATR FT-IR $(\mathrm{b}, \mathrm{d})$ of P(VDF-ter-TrFE-terCTFE) grafted with different benzophenone $(a, b)$ and anthraquinone $(c, d)$ contents.

The grafting degrees were calculated from the ${ }^{1} \mathrm{H}$ NMR spectra using the following equation and are gathered in Table 1.

Grafting degree $=\frac{\int_{7 p p m}^{8 p p m} \text { aromatic protons / number of protons per PI }}{\int_{5 p p m}^{6 p p m} C H F \text { of } \operatorname{TrFE}+\left(\int_{2.2 p p m}^{3.7 p p m} C H 2 \text { of } V D F\right) / 2+\left(\int_{6 p p m}^{6.7 p p m} C H \text { of double bonds }\right) * 2}$ 
Table 1. Reaction conditions and ${ }^{1} \mathrm{H}$ NMR data for P(VDF-ter-TrFE-ter-CTFE) grafted with benzophenone (BP) and anthraquinone (AQ) groups.

\begin{tabular}{|c|c|c|c|c|c|c|c|}
\hline & & $\begin{array}{l}\text { Equivalents of } \\
\text { PI }\end{array}$ & $\begin{array}{l}\text { Reaction } \\
\text { time }\end{array}$ & $\begin{array}{l}\operatorname{TrFE}(1 \mathrm{H}) \\
4.7-5.7 \mathrm{ppm}\end{array}$ & $\begin{array}{l}\text { Double } \\
\text { bonds }(1 \mathrm{H}) \\
6-7 \mathrm{ppm}\end{array}$ & $\begin{array}{l}\text { Aromatic } \\
7-8 \mathrm{ppm}\end{array}$ & $\begin{array}{l}\text { Grafting } \\
\text { degree }\end{array}$ \\
\hline & (1) & 0 & $0 \mathrm{~h}$ & 28.3 & $0 \%$ & 0 & $0 \%$ \\
\hline \multirow{3}{*}{ BP } & (2) & 0.3 & $4 \mathrm{~h}$ & 28.3 & $7.3 \%$ & $3.7(9 \mathrm{H})$ & $0.4 \%$ \\
\hline & (3) & 0.5 & $4 \mathrm{~h}$ & 28.3 & $7.1 \%$ & $9.2(9 \mathrm{H})$ & $1 \%$ \\
\hline & (4) & 0.5 & 3 days & 28.3 & $18 \%$ & $59(9 \mathrm{H})$ & $6.5 \%$ \\
\hline \multirow{3}{*}{ AQ } & (2) & 0.1 & 3 days & 28.3 & $6.2 \%$ & $4.4(8 \mathrm{H})$ & $0.6 \%$ \\
\hline & (3) & 0.3 & 3 days & 28.3 & $8.6 \%$ & $18.4(8 \mathrm{H})$ & $2.3 \%$ \\
\hline & (4) & 0.5 & 1 day & 28.3 & $14.6 \%$ & $46(8 \mathrm{H})$ & $6 \%$ \\
\hline
\end{tabular}

As discussed above, in addition to the desired substitution reaction, unsaturation was also created on the fluoropolymer's backbone (Scheme 3), due to the basic nature of the used phenoxides. The amount of double bonds was calculated for each polymer from the ${ }^{1} \mathrm{H}$ NMR spectra, as shown in Figure 1. The double bond contents are presented in Table 1. In all cases a considerable amount of double bonds was created, however the polymers maintained their solubility in common solvents such as cyclopentanone and dimethyl formamide (DMF), and that's mostly attributed to the two-step process that was followed which included the filtration of the base. In the cases that the base was not filtered off, the polymers would become black and lose their solubility. 


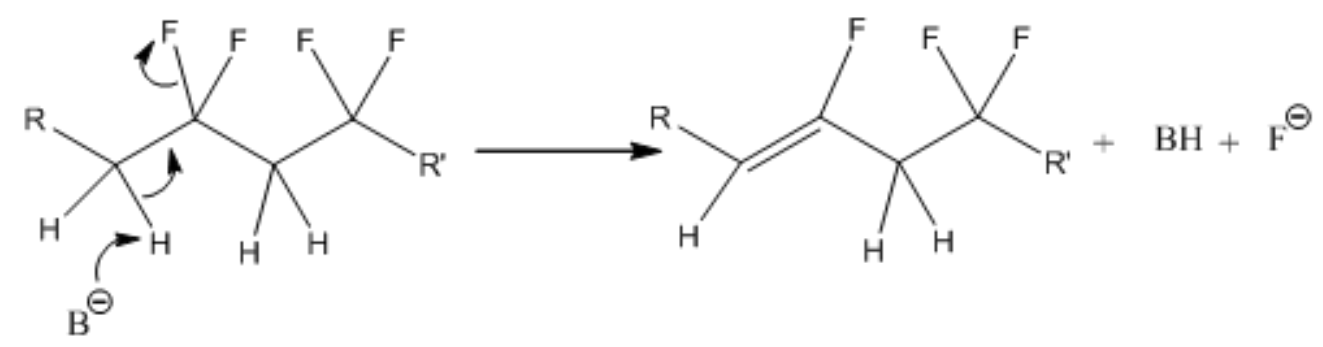

Scheme 3. Reaction of fluoropolymer with base leading to the formation of unsaturation on the polymer backbone.

\section{Structure and morphology characterization}

As the desired electroactive properties are known to derive from the crystalline state of these terpolymers ${ }^{20-21}$, differential scanning calorimetry (DSC) was used to get a first estimation of the effect that the modification reactions have on the polymer's crystallinity. After a first heating, we observed from the first cooling ramp (Figure 2a, c), that when the grafting degree was small ( $\leq$ $0.6 \%$ ), the crystallization peak becomes sharper for both photoinitiators, indicating more homogeneous crystal size distribution, while being approximately at the same temperature as the peak of the pristine polymer which is an indicator of similar nucleation process. However, with increasing the grafting degree, the crystallization peak shifts to lower temperature and for certain contents and above it totally disappears, indicating a progressive hindering of crystallization. During the second heating ramp, we observe a significant decrease of the melting enthalpy after grafting and a small decrease of the melting temperature for grafting degree higher than $1 \%$. The quantitative data derived for the DSCs are presented in Table 2. 


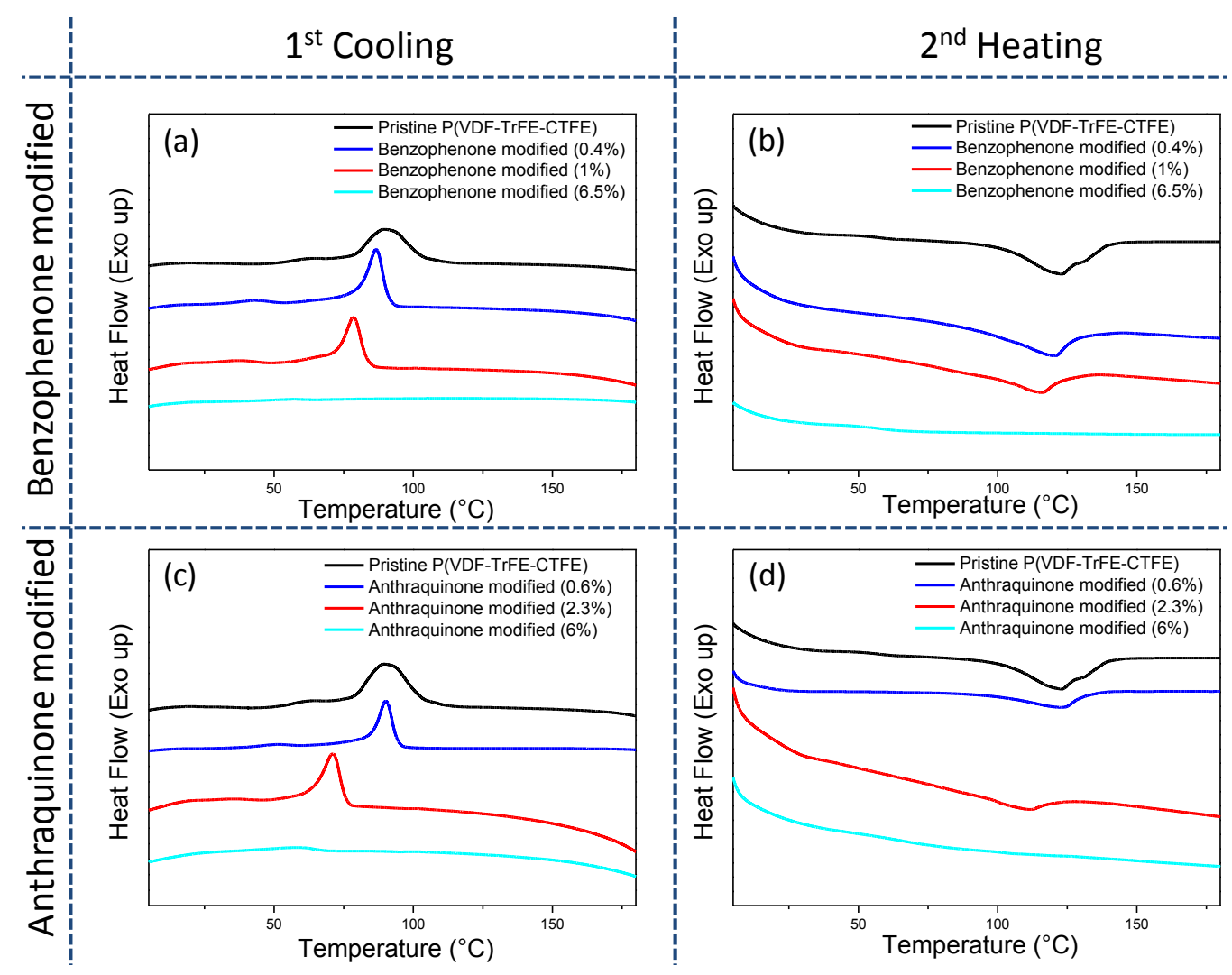

Figure 2. DSC thermograms showing the first cooling $(a, c)$ and second heating $(b, d)$ of P(VDFter-TrFE-ter-CTFE) grafted with different benzophenone $(\mathrm{a}, \mathrm{b})$ and anthraquinone $(\mathrm{c}, \mathrm{d})$ contents. 
Table 2. Summary of the data obtained by differential scanning calorimetry of pristine and BP and AQ modified PVDF-TrFE-CTFE terpolymer.

\begin{tabular}{|c|c|c|c|c|}
\hline \multirow{2}{*}{$\begin{array}{l}\text { As synthesized } \\
\text { samples }\end{array}$} & \multicolumn{2}{|c|}{ Crystallization } & \multicolumn{2}{|l|}{ Melting } \\
\hline & $\begin{array}{l}\text { Temperature } \\
\left({ }^{\circ} \mathrm{C}\right)\end{array}$ & $\begin{array}{l}\text { Enthalpy } \\
(\mathrm{J} / \mathrm{g})\end{array}$ & $\begin{array}{l}\text { Temperature } \\
\left({ }^{\circ} \mathrm{C}\right)\end{array}$ & $\begin{array}{l}\text { Enthalpy } \\
(\mathrm{J} / \mathrm{g})\end{array}$ \\
\hline Pristine terpolymer & 90 & 13 & 123 & 14 \\
\hline $\begin{array}{l}\text { Benzophenone } \\
(0.4 \%)\end{array}$ & 87 & 12 & 120 & 8 \\
\hline Benzophenone (1\%) & 79 & 9 & 116 & 5 \\
\hline $\begin{array}{l}\text { Benzophenone } \\
(6.5 \%)\end{array}$ & - & - & - & - \\
\hline $\begin{array}{l}\text { Anthraquinone } \\
(0.6 \%)\end{array}$ & 90 & 12 & 123 & 10 \\
\hline $\begin{array}{l}\text { Anthraquinone } \\
(2.3 \%)\end{array}$ & 71 & 7 & 110 & 3 \\
\hline Anthraquinone (6\%) & 59 & 0.9 & - & - \\
\hline
\end{tabular}

To understand the evolution of the crystalline phases with the chemical modification, we performed simultaneous SAXS-WAXS experiments on films as cast and after a $1 \mathrm{~h}$ annealing at $110^{\circ} \mathrm{C}$, below the melting temperature. Regardless of the modification degree, WAXS spectra (Figure 3) exhibit a main Bragg peak around $2 \theta=18^{\circ}$ superimposed on a broad signal associated to the amorphous phase. This Bragg peak is associated to the interplanar distances of the RFE orthorhombic pseudo-hexagonal phase described in a previous work ${ }^{14}$. When the degree of modification increases, the intensity of the RFE Bragg peak decreases considerably. Furthermore, the peak becomes asymmetric and it shifts toward higher $2 \theta$ angles. After annealing at $110^{\circ} \mathrm{C}$, below the melting temperature, an increase of the Bragg peak intensity is observed. 

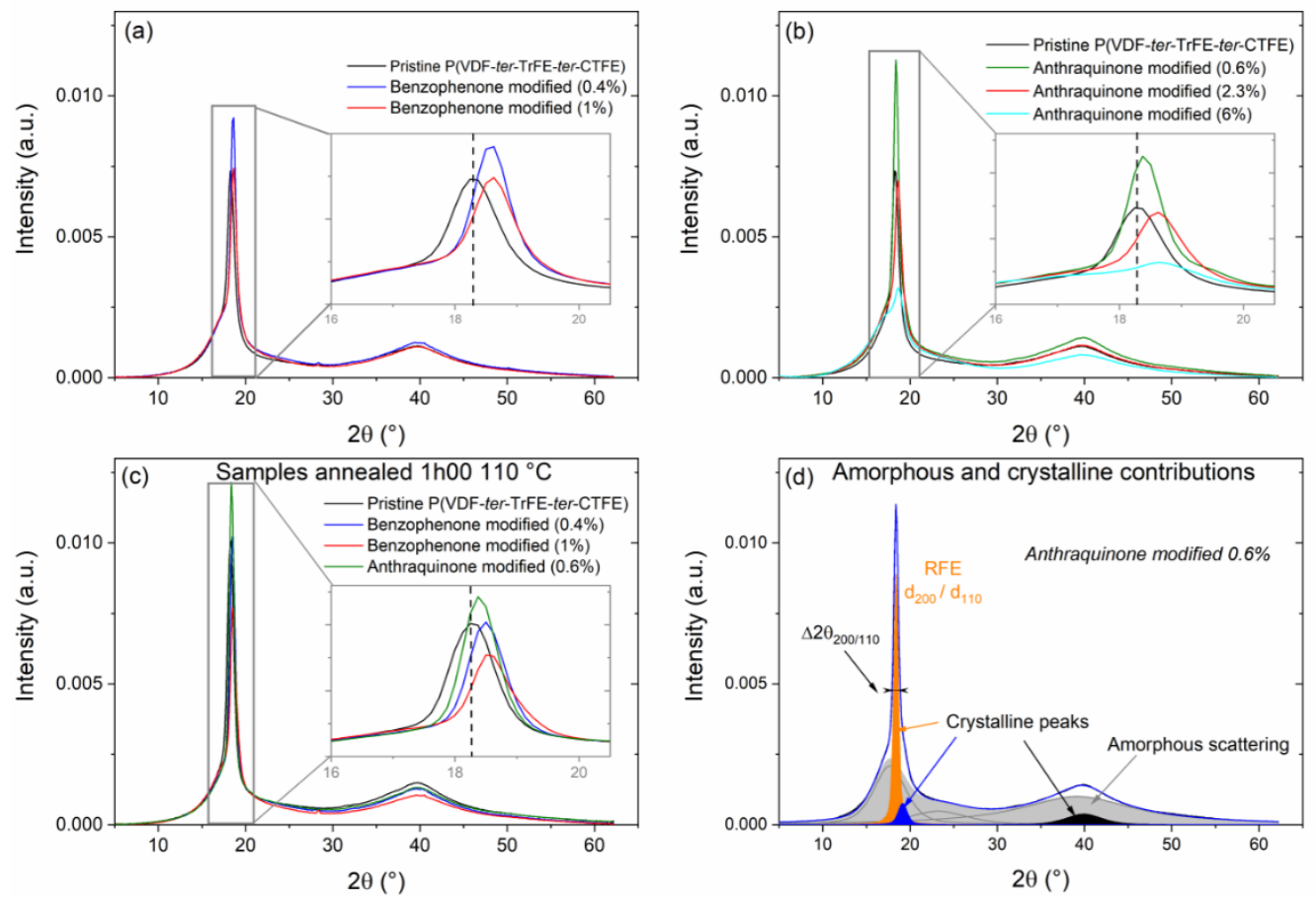

Figure 3. Evolution of the WAXS spectra for the modified fluorinated terpolymers for different contents of (a): benzophenone and (b): anthraquinone, $(a, b)$ : as cast and (c): after annealing at $110^{\circ} \mathrm{C}$ for $1 \mathrm{~h} 00$. An amplification on the main Bragg peak is shown on each picture (a),(b) and (c). (d): WAXS spectra decomposition for the quantitative analysis, amorphous phase appears in grey and the crystalline one in orange, blue and black.

The spectra are decomposed in broad and sharp peaks respectively associated with amorphous and crystalline phases (Figure 3d). Two crystalline peaks are sometimes needed to refine the main peak; these are the orange and blue ones. The Bragg peak, around $18^{\circ}$, is associated with interplanar distances perpendicular to the chain direction, it corresponds to the juxtaposition of two diffraction lines coming from the (200) and (110) planes of the pseudo-hexagonal structure. The width of this peak is due to both the separation of the two peaks $d_{200}$ and $d_{110}$ and the extension of the crystal ${ }^{14}$. The black peak around $2 \theta=40^{\circ}$ corresponds to the juxtaposition of 
several Bragg peaks mostly characteristic of the order along the chains ${ }^{22}$. The interplanar distance, $\mathrm{d}$, and the width, $\Delta 2 \theta$, of the main Bragg peak are reported in Table 3, along with the crystallinity $\chi_{\mathrm{c}}$.

Table 3. Summary of the data obtained by the simultaneous SAXS-WAXS experiments.

\begin{tabular}{|c|c|c|c|c|c|c|c|c|}
\hline \multirow[b]{2}{*}{ Drop cast films } & \multicolumn{4}{|c|}{ Before annealing } & \multicolumn{4}{|c|}{ After annealing, $1 \mathrm{~h} 00$ at $110^{\circ} \mathrm{C}$} \\
\hline & $\begin{array}{l}\mathrm{l} d \\
(\AA)\end{array}$ & $\begin{array}{l}{ }^{1} \Delta 2 \theta \\
\left(^{\circ}\right)\end{array}$ & $\begin{array}{l}\chi_{c} \\
(\%)\end{array}$ & $\begin{array}{l}\mathrm{L}_{\mathrm{P}} \\
(\AA)\end{array}$ & $\begin{array}{l}{ }^{\mathrm{d}} \\
(\AA)\end{array}$ & $\begin{array}{l}{ }^{1} \Delta 2 \theta \\
\left(^{\circ}\right)\end{array}$ & $\begin{array}{l}\chi_{c} \\
(\%)\end{array}$ & $\begin{array}{l}\mathrm{L}_{\mathrm{P}} \\
(\AA)\end{array}$ \\
\hline $\begin{array}{l}\text { Pristine } \\
\text { terpolymer }\end{array}$ & 4.84 & 0.85 & 20 & 300 & 4.85 & 0.82 & 23 & $\begin{array}{l}490 \\
(240)\end{array}$ \\
\hline $\begin{array}{l}\text { Benzophenone } \\
0.4 \%\end{array}$ & 4.77 & 0.7 & 21 & 250 & 4.79 & 0.7 & 24 & $\begin{array}{l}490 \\
\text { (200) }\end{array}$ \\
\hline Benzophenone $1 \%$ & 4.77 & 0.72 & 20 & 210 & 4.78 & 0.65 & 20 & $\begin{array}{l}330 \\
(175)\end{array}$ \\
\hline $\begin{array}{l}\text { Anthraquinone } \\
0.6 \%\end{array}$ & 4.82 & 0.62 & 21 & 280 & 4.82 & 0.66 & 24 & $\begin{array}{l}510 \\
(250)\end{array}$ \\
\hline $\begin{array}{l}\text { Anthraquinone } \\
2.3 \%\end{array}$ & 4.74 & 0.8 & 19 & 200 & - & - & - & - \\
\hline Anthraquinone $6 \%$ & 4.74 & 1.1 & 9 & 150 & - & - & - & - \\
\hline
\end{tabular}

${ }^{1} \mathrm{~d}$ is the interplanar distance associated with the Bragg peak (200)/(110) and $\Delta 2 \theta$ is their full width at the half maximum.

Chemical modification with Benzophenone (BP) or Anthraquinone (AQ) induces a decrease of the interplanar distance perpendicular to the chain direction and a thinning of the diffraction line. We deduce that the pendent groups, BP or AQ, are not incorporated in the crystalline phase. But surprisingly, the crystallinity does not decrease for small amount of modifications, less than $2 \%$. 
However, for high degree of chemical modification (>2\%) a decrease of the crystallinity and a broadening of the Bragg peak are observed, showing the degradation of the crystalline order. The thinning of the peak can be interpreted as an extension of the correlation length in the crystalline lamellae plane or as a small change of the crystalline cell toward the hexagonal phase.

The Lorentz-corrected SAXS spectra (Figure 4) show the evolution of the crystalline lamellae periodicity after chemical modifications and after annealing. From the maximum of these profiles, we deduced the period of the crystalline lamellae, $\mathrm{L}_{\mathrm{P}}$, this value is reported in Table 3.
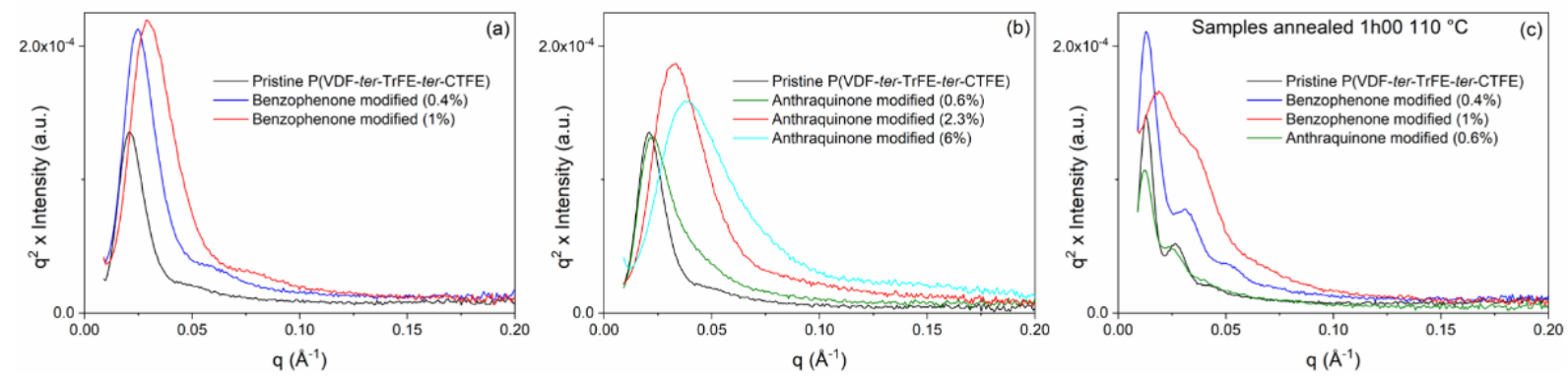

Figure 4. Evolution of the SAXS spectra for the fluorinated modified terpolymers for different contents of (a): benzophenone and (b): anthraquinone, $(a, b)$ : as cast and (c): after annealing at $110^{\circ} \mathrm{C}$ for $1 \mathrm{~h} 00$.

We observe a significant decrease of $L_{P}$ when the amount of chemical modification increases. This decrease is explained by the non-incorporation of the pendent group in the crystalline lamellae leading to a decrease of the crystalline lamellae thickness. At the same time, the intensity increases due to an increase of the contrast between crystalline and amorphous lamellae. Pendent groups localized at the crystalline and amorphous interface and in the amorphous phase modify the electronic density and then the contrast.

After annealing, a major reorganization of the crystalline lamellae is observed with a significant increase of $\mathrm{L}_{\mathrm{P}}$ and the appearance of well-defined second order diffraction peak. For 
the lowest chemical modifications, $0.4 \% \mathrm{BP}$ and $0.6 \% \mathrm{AQ}$, the long periods, $\mathrm{L}_{\mathrm{P}}$, are comparable with the period of the non-modified terpolymer. Only the intensity differs, as the crystallinities are comparable (23-24\%), we conclude on differences in electronic density and/or in localization of $\mathrm{BP}$ or $\mathrm{AQ}$ pendent groups.

In order to visualize the effect that the modification has on the morphology of the polymers, spin coated films prepared with the anthraquinone modified fluoropolymers were characterized by Atomic Force Microscopy (AFM) in tapping mode. The phase images, shown in Figure 5, confirm that for low anthraquinone content $(0.6 \%)$, the terpolymer's rod-like crystalline domains become larger with more homogeneous size distribution (Figure 5b). But when the anthraquinone content increases to $2.3 \%$ the morphology become granular and the domain size much smaller, (Figure 5c) and finally the grains decrease even further in size for $6 \%$ anthaquinone content. 

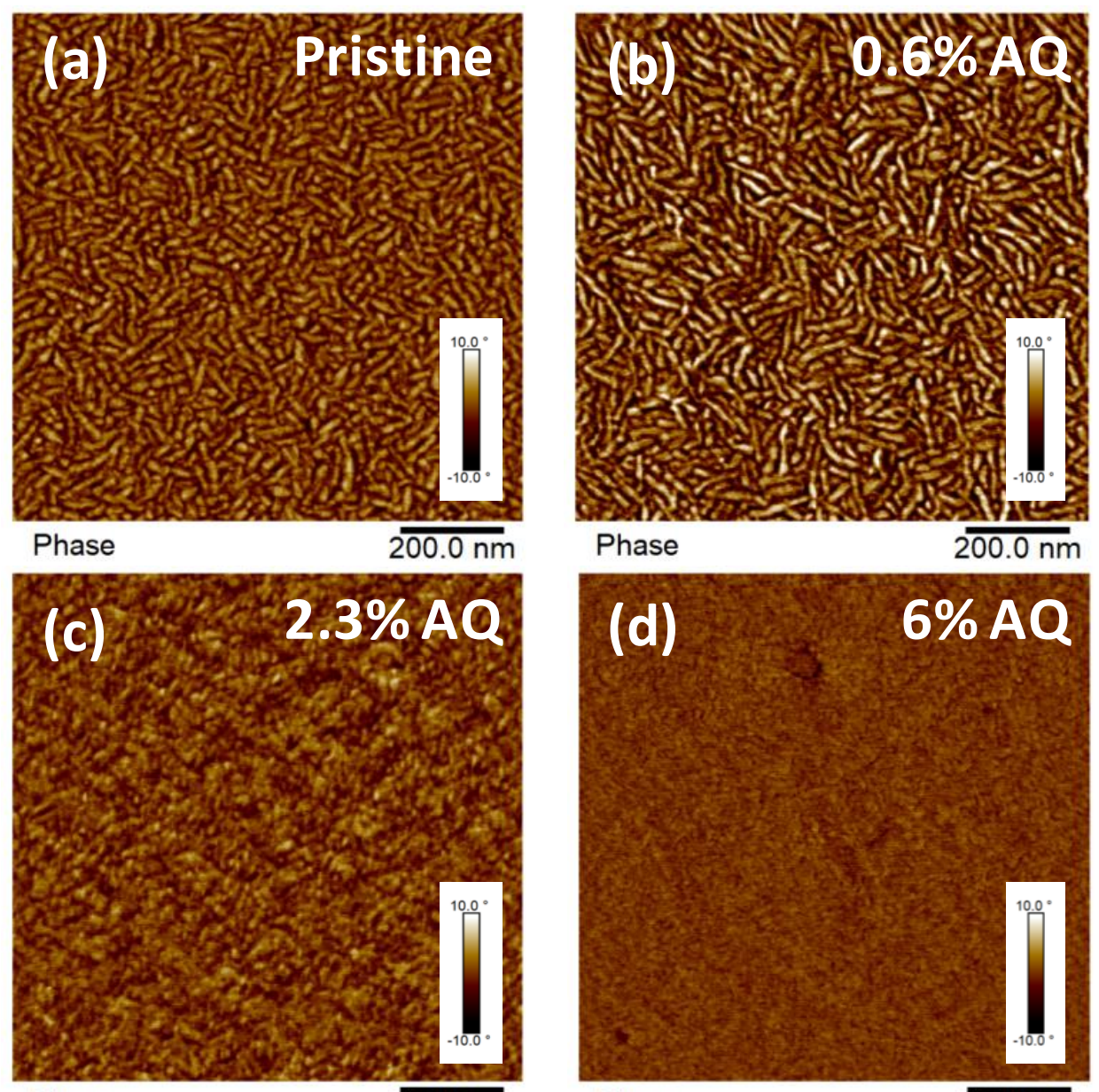

Phase
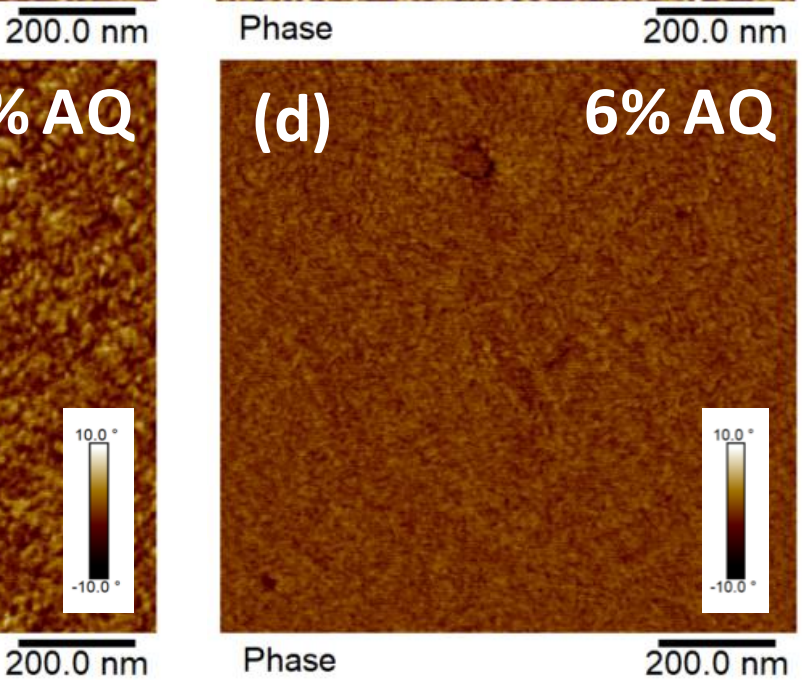

Figure 5. Phase AFM images of as-cast films of the pristine (a) and the anthraquinone modified $\mathrm{P}(\mathrm{VDF}-\mathrm{ter}$-TrFE-ter-CTFE) terpolymers with various anthraquinone contents.

Although the crystallinity obtained by solvent casting (SAXS-WAXS) is higher than that obtained by cooling from the melt (DSC), interesting correlations can be established between the SAXS-WAXS and DSC experiments. From WAXS measurements, we conclude that the pendent group BP and AQ are not incorporated in the crystal. The expulsion of the pendent group before crystallization explain the shift of the crystallization exotherm measured in DSC. Due to their non-incorporation in the crystal, a high amount of modification ( $>6 \%)$ hinders the crystallization. For low amount of modification $(<1 \%)$, the decrease of the interplanar distance, the stability of 
the crystallinity and the significant decrease of the Bragg peak width would indicate a perfection of the crystalline order in the plane of the crystalline lamellae which can explain the observed thinning of the crystallization exotherm and the well-defined morphology observed by AFM. The decrease of the crystalline lamellae thickness explains the decrease in melting temperature.

\section{Photoresponsive properties}

Self-standing films of the polymers grafted with benzophenone and anthraquinone groups were characterized by UV-Vis spectroscopy (Figure 6). Both polymers show strong deep UV absorption peaks, however, the terpolymer grafted with anthraquinone groups shows an additional i-line absorption peak.

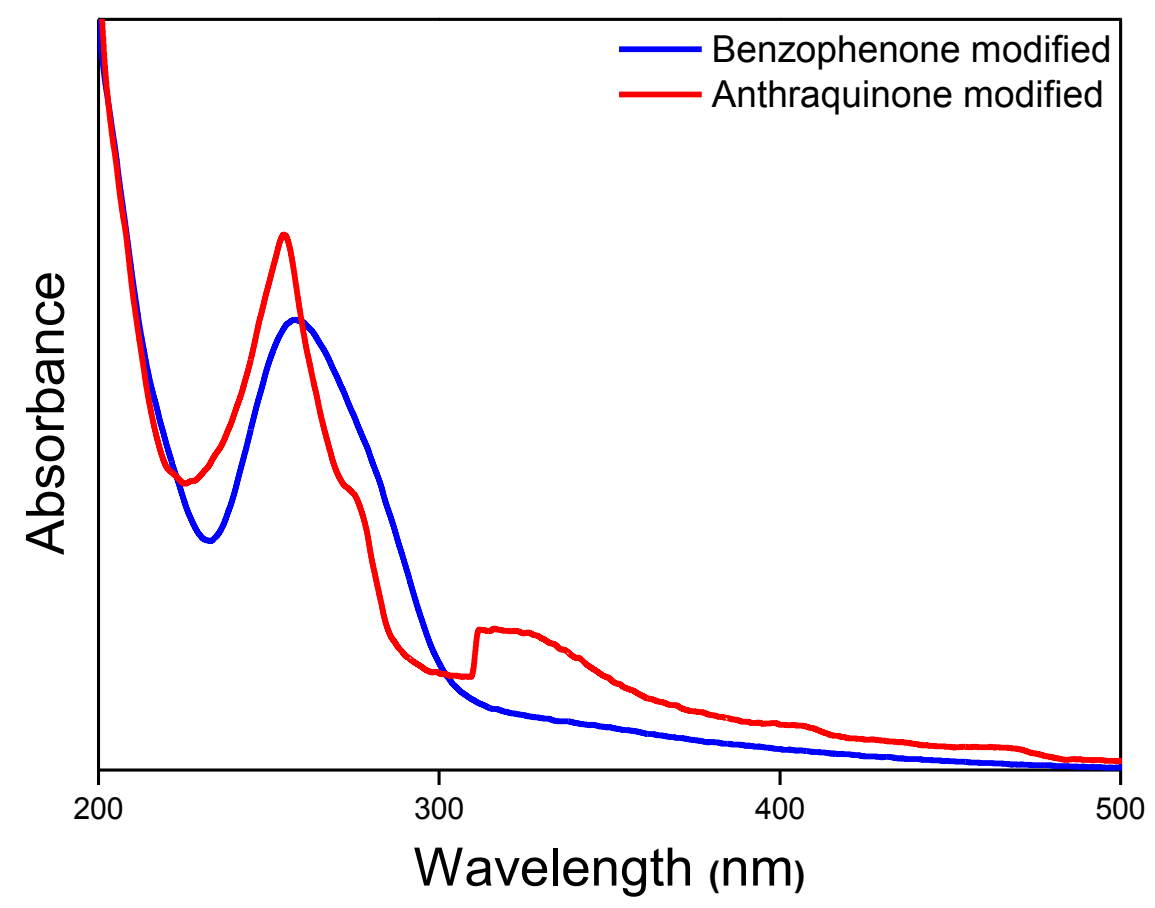

Figure 6. UV-Vis absorption of self-standing films of P(VDF-ter-TrFE-ter-CTFE) modified with benzophenone (blue) and anthraquinone (red). 
As mentioned above, one of the reasons that the benzophenone and anthraquinone groups were chosen is that they act as type II photoinitiators. So when polymers bearing those chromophores get exposed to UV light, triplet ketyl biradicals are reversibly formed by transferring of a nonbonding electron from the carbonyl oxygen to the carbonyl $\pi^{*}$ orbital $^{23}$, as described in Scheme 4. If the biradical does react during its half-life, the chromophore will return to its ground state and will be available for further excitation. However, if the ketyl biradical abstracts a hydrogen from a neighboring polymer chain, it will turn to a ketyl radical and a new alkyl radical will be formed on that chain. Subsequently, neighboring radicals can recombine leading to the formation of a $\mathrm{C}-\mathrm{C}$ bond and a cross-linked polymer network. Alternatively the ketyl radicals can insert in $\mathrm{C}-\mathrm{H}$ bonds (CHic-reaction) also leading to the formation of a cross-linked network $^{24}$ as shown in Scheme 4. The cross-linking mechanisms are almost identical for both photoinitiators.

A.

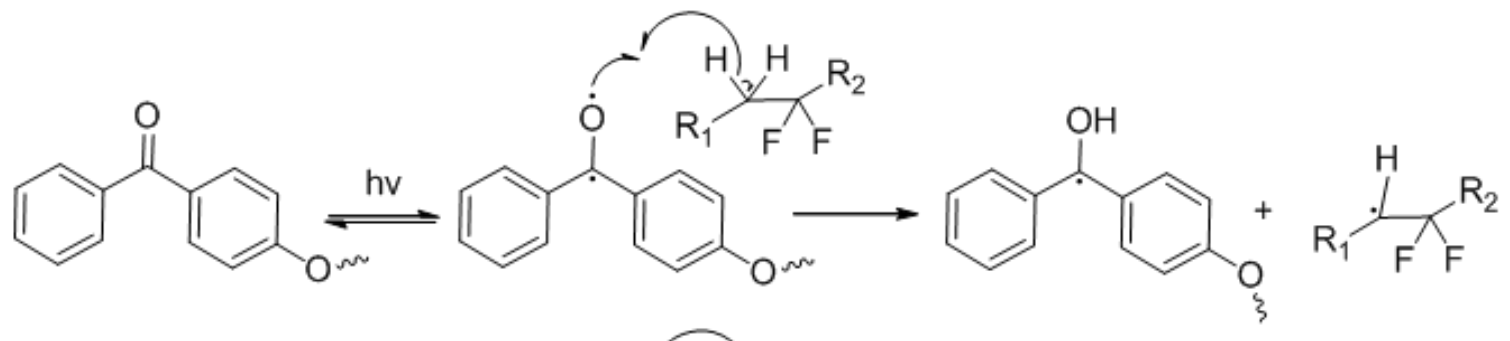

B.

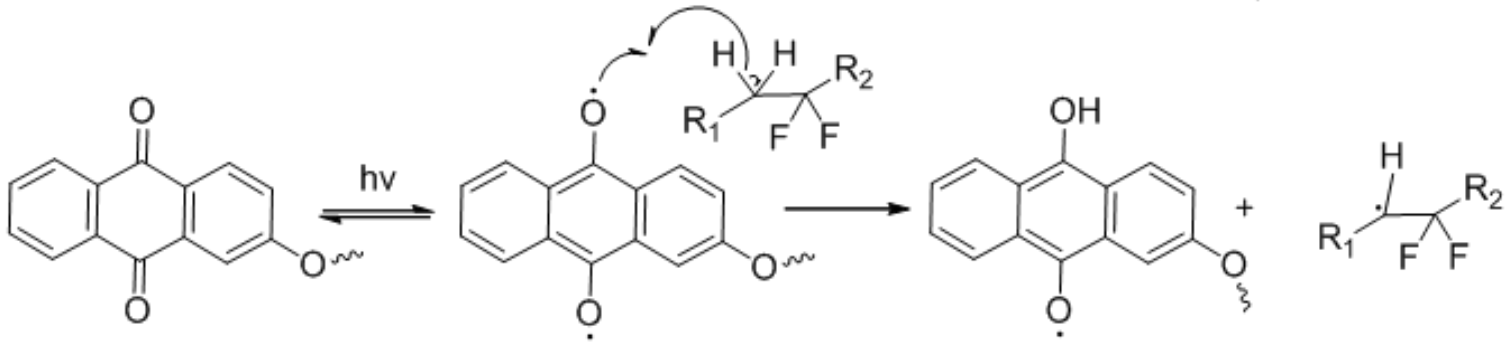

Scheme 4. Reversible excitation of the benzophenone (A) and anthraquinone (B) moieties upon irradiation with UV light and subsequent hydrogen abstraction leading to the formation of free radicals on the polymer backbone. 


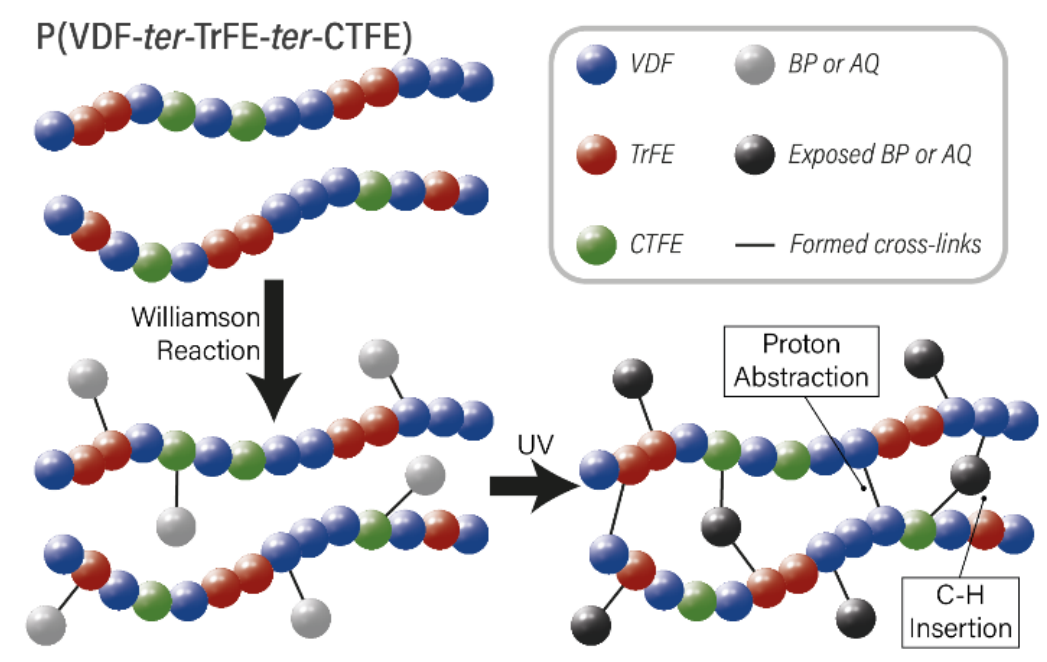

Figure 7. Schematic representation of the photo induced cross-linking of P(VDF-ter-TrFE-terCTFE) polymers bearing either benzophenone or anthraquinone pendent groups.

Photolithographic patterning processes were developed for fluoropolymers bearing both photoinitiators. The ultra-high molar mass of the used polymers, with polymerization degree over 2000, allows for very low cross-linker contents to be sufficient for an infinite network to be rapidly formed at low UV dose. Optical microscopy images of the patterned films are shown in Figures S 10, 11.

\section{Dielectric and ferroelectric properties}

The impact of the different modification reactions on the dielectric properties was investigated by broadband dielectric spectroscopy at temperatures ranging from $20^{\circ} \mathrm{C}$ to $80^{\circ} \mathrm{C}$. The real part of the relative permittivity $\left(\varepsilon_{\mathrm{r}}^{\prime}\right)$ at $1 \mathrm{kHz}$ of the terpolymers grafted with different contents of benzophenone (BP) and anthraquinone (AQ) was assessed in three different cases. Firstly, the polymers were characterized as cast without any further treatment (Figure $8 \mathrm{a}, \mathrm{b}$ ), then similar films were annealed at $110^{\circ} \mathrm{C}$ for $1 \mathrm{~h}$ and let slowly cool down (Figure $8 \mathrm{c}, \mathrm{d}$ ) and finally, films were exposed at UV light and then annealed (Figure 8 e, f). It was observed that the polymers 
grafted with low amounts of benzophenone $(0.4 \%)$ and anthraquinone $(0.6 \%)$ showed improved performance in terms of dielectric properties in all cases, while increasing either the benzophenone or the anthraquinone content leads to deteriorated properties. The highest observed enhancement in dielectric properties occurred for the annealed anthraquinone $(0.6 \%)$ polymer, where a $60 \%$ increase in relative permittivity was observed at the peak temperature $\left(40^{\circ} \mathrm{C}\right)$, with the relative permittivity up to 65 compared to 40 for the pristine polymer. The annealing step was shown to improve the dielectric properties of all films, however, the largest improvement was again observed for this particular anthraquinone modified polymer $(0.6 \%)$ polymer, as shown in (Figure 8). Exposure to UV light $\left(6 \mathrm{~J} / \mathrm{cm}^{2}\right)$ was shown to have a negative impact on the dielectric properties of the various polymers (Figure $8 \mathrm{e}, \mathrm{f}$ ). However, despite the slight decrease in $\varepsilon_{\mathrm{r}}^{\prime}$ for the exposed films, the benzophenone $(0.4 \%)$ and anthraquinone $(0.6 \%)$ polymers still exhibited enhanced properties compared to the pristine $\mathrm{P}(\mathrm{VDF}-$ ter-TrFE-terCTFE), which was used as a reference. 

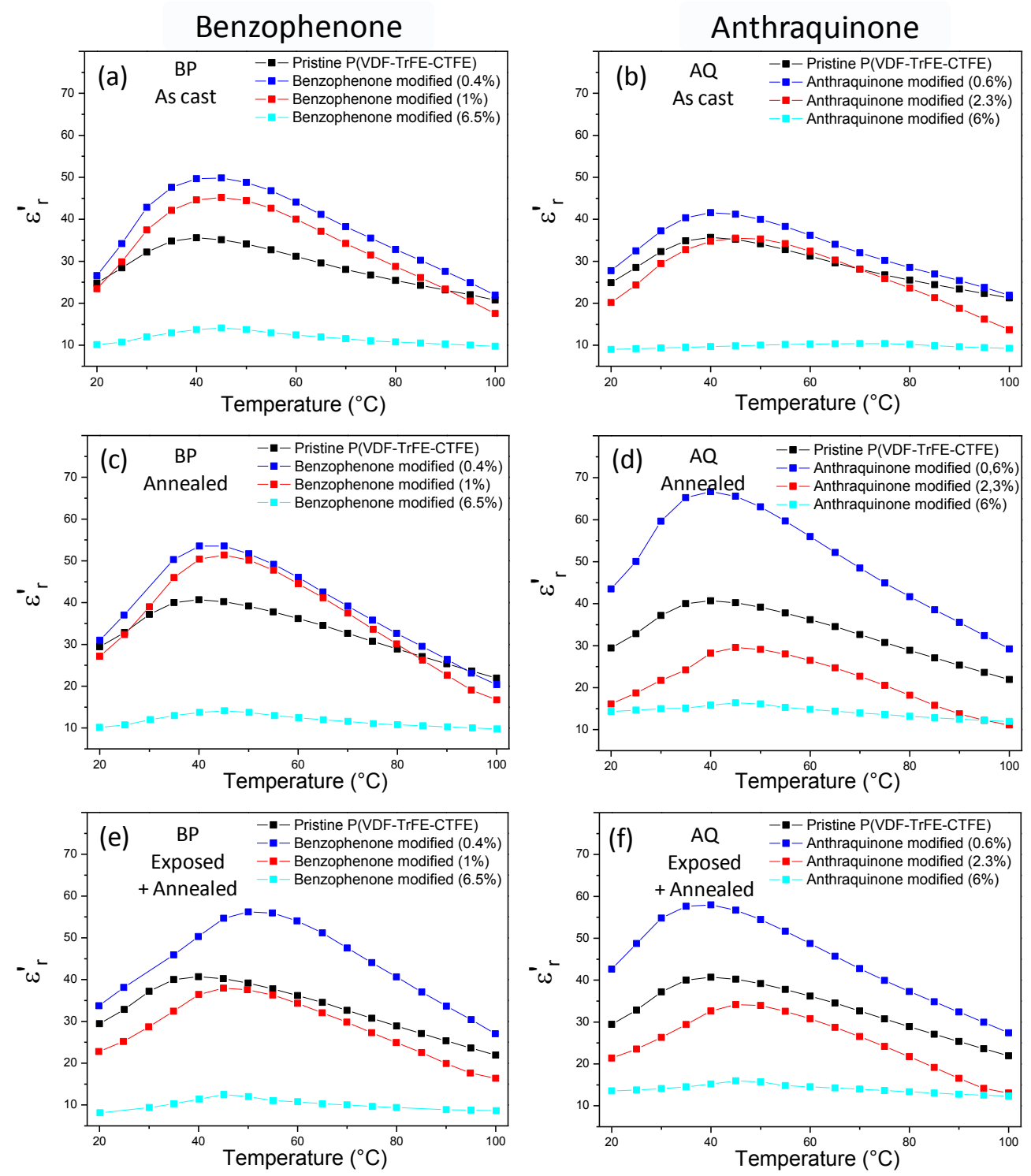

Figure 8 . Real part of the relative permittivity $(1 \mathrm{kHz})$ as a function of temperature for P(VDFter-TrFE-ter-CTFE) functionalized with different contents of benzophenone (left) and anthraquinone (right) as cast $(\mathrm{a}, \mathrm{b})$ as annealed at $110^{\circ} \mathrm{C}$ for $1 \mathrm{~h}(\mathrm{c}, \mathrm{d})$ and after exposure to $6 \mathrm{~J} / \mathrm{cm}^{2}$ of UV light and subsequent annealing.

A similar pattern was observed in the evolution of the ferroelectric properties with increasing the photoinitiator (PI) content. Again, the films were characterized in three steps, as cast (Figure $9 \mathrm{a}, \mathrm{b}, \mathrm{e}, \mathrm{f}$ ), after annealing (Figure $9 \mathrm{c}, \mathrm{d}, \mathrm{g}, \mathrm{h}$ ) and finally after exposure to UV light and 
subsequent annealing (Figure S 12). Enhanced ferroelectric response was observed in all three steps of characterization for the low PI content polymers.

The annealing step had no great impact in the ferroelectric properties, contrarily to the dielectric properties, where the impact was much more pronounced. At high PI contents the polymers behave as linear dielectrics, as no crystallinity is observed and all dipoles are located in the amorphous lattice and thus do not interact with each other, giving rise to almost zero hysteresis, characteristic of linear dielectrics. 

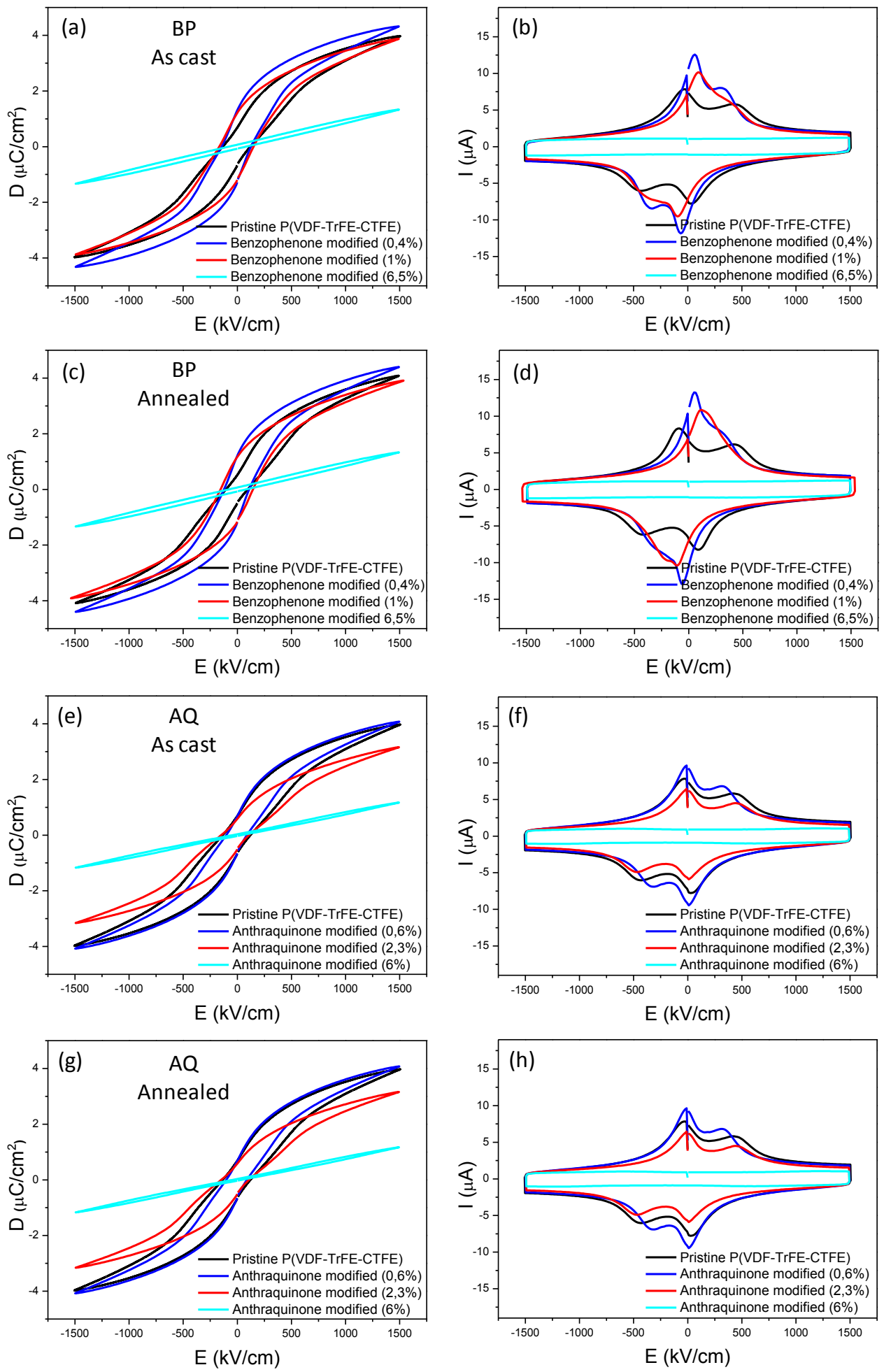
Figure 9. Ferroelectric testing at room temperature of $\mathrm{P}(\mathrm{VDF}$-ter-TrFE-ter-CTFE) functionalized with different contents of benzophenone (BP) and anthraquinone (AQ), before and after annealing at $110^{\circ} \mathrm{C}$ for $1 \mathrm{~h}$. Displacement (left) and current (right).

\section{CONCLUSIONS}

A general method enabling the introduction of additional functionality to FEPs was developed in this work. Relaxor-ferroelectric P(VDF-ter-TrFE-ter-CTFE) polymers were functionalized with photoinitiator groups via a simple etherification reaction and the produced cross-linkable polymers exhibited in some cases enhanced electroactive properties even when compared to the state of the art pristine polymers. The enhancement in terms of relative permittivity was as much as $60 \%$ for the anthraquinone $(0.6 \%)$ containing polymer, where the dielectric constant increased from 40 to 65 at $40^{\circ} \mathrm{C}$. That property enhancement was attributed to the perfection of the crystalline order, expressed by the decrease of the interplanar distance and the Bragg peak width. Despite this method being used in the context of this report primarily to induce photopatternability and tune the electroactive properties of FEPs, it's by no means limited to such use, as it allows for the grafting of different functional groups in different kinds of fluorinated polymers.

\section{ASSOCIATED CONTENT}

Supporting Information. The following files are available free of charge.

Figure S1. ${ }^{19}$ F-NMR at $376,5 \mathrm{MHz}$ of benzophenone grafted P(VDF-ter-TrFE-ter-CTFE) terpolymer. Figure S2. SEC in DMF of the pristine and the benzophenone grafted P(VDF-terTrFE-ter-CTFE) terpolymer with $6.5 \%$ benzophenone content. Figure S $3 .{ }^{19}$ F-NMR at 376,5 
MHz of anthraquinone grafted P(VDF-ter-TrFE-ter-CTFE) terpolymer. Figure S 4. SEC in DMF of the pristine and the anthraquinone grafted $\mathrm{P}(\mathrm{VDF}$-ter-TrFE-ter-CTFE) terpolymer with $0.6 \%$ anthraquinone content. Figure S 5. Thermal gravimetric analysis of the pristine and the anthraquinone grafted P(VDF-ter-TrFE-ter-CTFE) terpolymer with $0.6 \%$ anthraquinone content. Figure S 6. FT-IR spectra of 4-hydroxybenzophenone. Figure S 7. FT-IR spectra of 2hydroxyanthraquinone. Figure S 8. Optical microscope picture of patterned benzophenone modified P(VDF-ter-TrFE-ter-CTFE) terpolymer. Figure S 9. Optical microscope picture of patterned anthraquinone modified $\mathrm{P}(\mathrm{VDF}-$ ter-TrFE-ter-CTFE) terpolymer. Figure S 10. Ferroelectric testing at room temperature of $\mathrm{P}(\mathrm{VDF}-$ ter-TrFE-ter-CTFE) functionalized with different benzophenone and anthraquinone contents.

\section{AUTHOR INFORMATION}

\section{Corresponding Author}

* georges.hadziioannou@u-bordeaux.fr

\section{Author Contributions}

All authors have given approval to the final version of the manuscript.

\section{Notes}

The authors declare no competing financial interest.

\section{ACKNOWLEDGMENT}

The authors acknowledge the financial support from Arkema and Région Aquitaine as well as from the Industrial Chair (Arkema/ANR) within the grant agreement no. AC-2013-365. K.K. acknowledges the Région Aquitaine for the financial support (Ph.D. grant \#2015-1R1020700004862). This work was performed within the framework of the Equipex ELORPrintTec ANR-10-EQPX-28-01 with the help of the French state's Initiative d'Excellence IdEx ANR-10IDEX-003-02. Sylvie Tencé-Girault's contribution was achieved within the framework of the Industrial Chair Arkema (Arkema/CNRS-ENSAM-CNAM). 


\section{ABBREVIATIONS}

k, dielectric constant; FEP, fluorinated electroactive polymer; OFET, organic field effect transistor; $\varepsilon_{\mathrm{r}}^{\prime}$, real part of the relative permittivity; Tan $\delta$, dielectric loss; $\mathrm{BP}$, benzophenone; $\mathrm{AQ}$, anthraquinone; PI, photo initiator;

\section{REFERENCES}

1. MacDiarmid, A. G., "Synthetic Metals": A Novel Role for Organic Polymers (Nobel Lecture). Angewandte Chemie International Edition 2001, 40 (14), 2581-2590.

2. Facchetti, A., $\pi$-Conjugated Polymers for Organic Electronics and Photovoltaic Cell Applications. Chemistry of Materials 2011, 23 (3), 733-758.

3. Soulestin, T.; Ladmiral, V.; Dos Santos, F. D.; Ameduri, B. J. P. i. P. S., Vinylidene fluoride-and trifluoroethylene-containing fluorinated electroactive copolymers. How does chemistry impact properties? Progress in Polymer Science 2017, 72, 16-60.

4. Lovinger, A. J. J. S., Ferroelectric polymers. Science 1983, 220 (4602), 1115-1121.

5. Zhang, Q. M.; Bharti, V.; Zhao, X., Giant Electrostriction and Relaxor Ferroelectric Behavior in Electron-Irradiated Poly(vinylidene fluoride-trifluoroethylene) Copolymer. Science 1998, 280 (5372), 2101-2104.

6. Terzic, I.; Meereboer, N. L.; Acuautla, M.; Portale, G.; Loos, K., Electroactive materials with tunable response based on block copolymer self-assembly. Nature Communications 2019, $10(1), 601$.

7. $\quad$ Meereboer, Niels L.; Terzić, I.; van der Steeg, P.; Portale, G.; Loos, K., Physical pinning and chemical crosslinking-induced relaxor ferroelectric behavior in P(VDF-ter-TrFE-ter-VA) terpolymers. Journal of Materials Chemistry A 2019, 7 (6), 2795-2803.

8. Abusleme, J. A.; Maccone, P., Polymerization process in aqueous emulsion of fuluorinated olefinic monomers. Google Patents: 1996.

9. Dos Santos, F. D.; Lannuzel, T., Method for preparation of derivatives of polyvinylidene fluoride. Google Patents: 2017.

10. Guan, F.; Wang, J.; Yang, L.; Tseng, J.-K.; Han, K.; Wang, Q.; Zhu, L., ConfinementInduced High-Field Antiferroelectric-like Behavior in a Poly(vinylidene fluoride-cotrifluoroethylene-co-chlorotrifluoroethylene)-graft-polystyrene Graft Copolymer. Macromolecules 2011, 44 (7), 2190-2199.

11. Guan, F.; Yang, L.; Wang, J.; Guan, B.; Han, K.; Wang, Q.; Zhu, L., Confined Ferroelectric Properties in Poly(Vinylidene Fluoride-co-Chlorotrifluoroethylene)-graftPolystyrene Graft Copolymers for Electric Energy Storage Applications. Advanced Functional Materials 2011, 21 (16), 3176-3188.

12. Rahimabady, M.; Qun Xu, L.; Arabnejad, S.; Yao, K.; Lu, L.; Shim, V. P.; Gee Neoh, K.; Kang, E.-T., Poly (vinylidene fluoride-co-hexafluoropropylene)-graft-poly (dopamine methacrylamide) copolymers: A nonlinear dielectric material for high energy density storage. Applied Physics Letters 2013, 103 (26), 262904. 13. Kallitsis, K.; Thuau, D.; Soulestin, T.; Brochon, C.; Cloutet, E.; Dos Santos, F. D.; Hadziioannou, G., Photopatternable High-k Fluoropolymer Dielectrics Bearing Pendent Azido Groups. Macromolecules 2019, 52 (15), 5769-5776. 
14. Bargain, F.; Thuau, D.; Panine, P.; Hadziioannou, G.; Domingues Dos Santos, F.; TencéGirault, S., Thermal behavior of poly(VDF-ter-TrFE-ter-CTFE) copolymers: Influence of CTFE termonomer on the crystal-crystal transitions. Polymer 2019, 161, 64-77.

15. Boschet, F.; Ameduri, B., (Co)polymers of Chlorotrifluoroethylene: Synthesis, Properties, and Applications. Chemical Reviews 2014, 114 (2), 927-980.

16. Kise, H.; Ogata, H.; Nakata, M., Chemical dehydrofluorination and electrical conductivity of poly(vinylidene fluoride) films. Die Angewandte Makromolekulare Chemie 1989, 168 (1), 205-216.

17. Kallitsis, K. J.; Nannou, R.; Andreopoulou, A. K.; Daletou, M. K.; Papaioannou, D.; Neophytides, S. G.; Kallitsis, J. K., Crosslinked wholly aromatic polyether membranes based on quinoline derivatives and their application in high temperature polymer electrolyte membrane fuel cells. Journal of Power Sources 2018, 379, 144-154.

18. Kim, J.; Hanna, J. A.; Byun, M.; Santangelo, C. D.; Hayward, R. C., Designing responsive buckled surfaces by halftone gel lithography. Science 2012, 335 (6073), 1201-5.

19. Schwärzle, D.; Hou, X.; Prucker, O.; Rühe, J., Polymer Microstructures through TwoPhoton Crosslinking. Advanced Materials 2017, 29 (39), 1703469.

20. Li, M.; Wondergem, H. J.; Spijkman, M.-J.; Asadi, K.; Katsouras, I.; Blom, P. W. M.; de Leeuw, D. M., Revisiting the $\delta$-phase of poly(vinylidene fluoride) for solution-processed ferroelectric thin films. Nature materials 2013, 12, 433.

21. Yang, L.; Li, X.; Allahyarov, E.; Taylor, P. L.; Zhang, Q. M.; Zhu, L., Novel polymer ferroelectric behavior via crystal isomorphism and the nanoconfinement effect. Polymer 2013, 54 (7), 1709-1728.

22. Bargain, F.; Panine, P.; Dos Santos, F. D.; Tence-Girault, S., From solvent-cast to annealed and poled poly (VDF-co-TrFE) films: New insights on the defective ferroelectric phase. Polymer 2016, 105, 144-156.

23. Preston, G. W.; Wilson, A. J., Photo-induced covalent cross-linking for the analysis of biomolecular interactions. Chemical Society Reviews 2013, 42 (8), 3289-3301.

24. Körner, M.; Prucker, O.; Rühe, J., Kinetics of the Generation of Surface-Attached Polymer Networks through C, H-Insertion Reactions. Macromolecules 2016, 49 (7), 2438-2447. 